\title{
Community Public Facilities Planning and Study of Shenzhen Pingshan New District
}

\author{
Xuefeng ZHAO \\ Shenyang University \\ Shenyang, China \\ e-mail: $446489101 @ q q . c o m$
}

\author{
Yangyang LIU \\ GS Research Center of Shenyang Jianzhu University \\ Shenyang, China \\ e-mail: 504739906@qq.com
}

\begin{abstract}
The paper based on the urban floating population represents a significant share of Shenzhen Pingshan new district as an example, analyze the economy, identity, cultural level, of present population. According to the development of Pingshan new district; divide present community into four types, include Comprehensive, living, industry and ecological, according to the characteristics of different types urban community development, reference Shenzhen city planning standards and guidelines, put forward the differentiation of configuration method, standard and layout method.
\end{abstract}

Keywords-floating population; city community; public facilities; differentiation

\section{INTRODUCTION}

Floating population refers to a period of time to leave the residence location, across a certain geographical boundaries to live, live and work and a series of activities, and there is no migration of the population of the household registration. In our country, many cities have a large number of floating populations, there is no local household registration, and they are live in the city of residents.

At present our country statistics and management of the floating population exists some difficulties, in consideration of urban basic public service facilities are mostly from the household population of, less attention has been given to floating population demand for public services, leading to a conflict arises between the overall development of the urban public service facilities, allocation and the city. The paper is the example of Shenzhen Pingshan district, because Pingshan have large proportion of floating population. Based on the characteristics of community development, the development goal is to enhance the community function. So we should start from the point of view of solving the problem, the strategy of community public facilities planning is put forward, including the construction of multi-level public service network strategy, the establishment of differentiated supply strategy, facilities, intensive layout strategy and the development of multilateral cooperation strategy.

\section{THE DEVELOPMENT CHARACTERISTICS AND PROBLEMS FOR THE FLOATING POPULATION AND URBAN PUBLIC SERVICE FACILITIES IN SHENZHEN PINGSHAN NEW DISTRICT}

\section{A. Under the Background of Urbanization, the Floating Population Increase Rapidly and the Population Structure Complex}

Pingshan district is located in the northeast of Shenzhen, a major industrial base in Shenzhen east, an important strategic node of deepening cooperation deep this. I would like. In Pingshan New Distinct, there are 2 streets that have the jurisdiction over 23 communities. The total population of the hole district is 602000 people, in which there are 286000 people are floating population, and 316000 people are permanent resident population. The current population structure of Pingshan New District is rather special. The permanent resident population accounts for $53 \%$ of the proportion of the total population, household register population accounts for only $13 \%$ of the population of permanent residents, and major part of the permanent resident population in city is the floating population. The structure features of the urban population structure presents as indigenous people are less, floating people are more, as shown in the figure below.

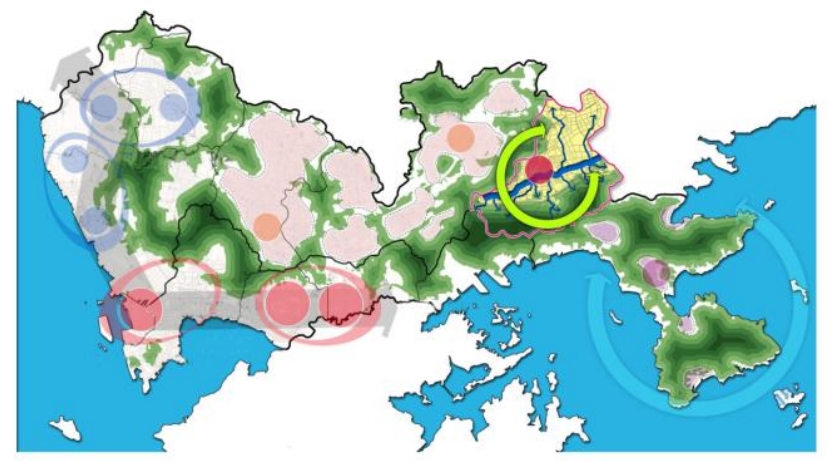

Figure 1. Geographical location of Pingshan new district

\section{B. A Lack of Public Service Facility, Difficult to Meet Population Developing Demand}

At present, public service facility mainly includes seven kinds, education facility, medical facility, sports facility, administrative management and community service facility, social welfare facility, municipal facility and so on. In current circumstance, public service facility construction in Pingshan New District does not match population size. Some of the construction number is less, is difficult to guarantee 
the quality, lacks after-maintenance and have other problems of management mode. That leads to cannot meet urban resident everyday demand and higher request to living quality in the statement of rapid development of urbanization and urban floating population. Please see 1 to know the content, sorts and main problems of every service facility in Pingshan New District.

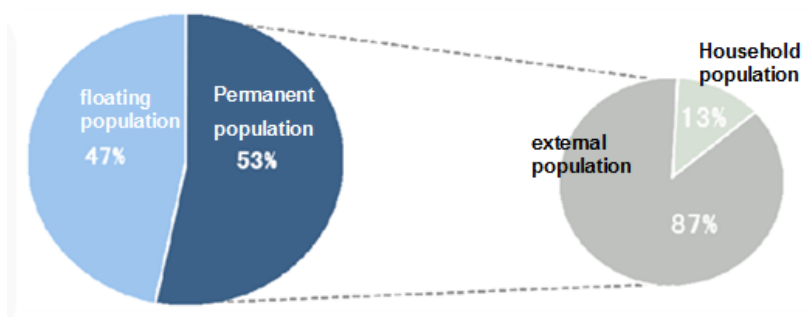

Figure 2. Population structure of Pingshan new district

\section{Different Characteristics of the Community Development, It is Difficult to Unify the Public Service Facilities Allocation Standards}

Now there are 2 streets that have the jurisdiction over 23 communities. These communities have different features because of the different population structure, geographical location, industrial structure and nature environment. Therefore, the demand of community public supporting facility is different. The supporting facility according to the standard in use cannot completely meet the residents' demand. Every community scope and population distribution is different. Pingshan Community and Kengzi Community respectively locate in the center areas of the two streets, which have the features of large population density and small community scope, so the construction according to population size or service radius in the construction process of community public facility will make differences between the result and actual use. The features of the existing facility in different communities in Shenzhen Pingshan.

\section{STUDY ON THE DIFFERENCES OF PINGSHAN NEW DisTRICT PUBLIC SERVICE FACILITIES DEMAND}

\section{A. Division of Community Types Conducive to the Facility Configuration}

Now there are 2 streets that have the jurisdiction over 23 communities, divided into four types: integrated community, residential community, industrial community and ecological community.

- General community is located in the more developed areas of the city center area, stream of people logistics intensive, with the tension. Work, entertainment, leisure, shopping and other functional service facilities within the Comprehensive community, at the same time, a high level of public service facilities, complete.

- Residential community is to live for the main function of the community, and in the combination of urban and rural, poor environment, more mobile population, population structure is complex, a serious lack of facilities, so need more to provide the service life of facilities for residents.

- Industrial type community is mainly based on industrial enterprises, living as a supplement, according to the needs of industrial workers, managers and employees to support the construction of life service area. Industrial type community population is the industrial park staff; the age structure presents the characteristics of youth, structural hybrid.

- All or part of the ecological community is in the scope of the ecological control line, the construction land is less, the community population is small, and the distribution is scattered. Facilities service radius and location are very difficult, the future development of a strong constraint.

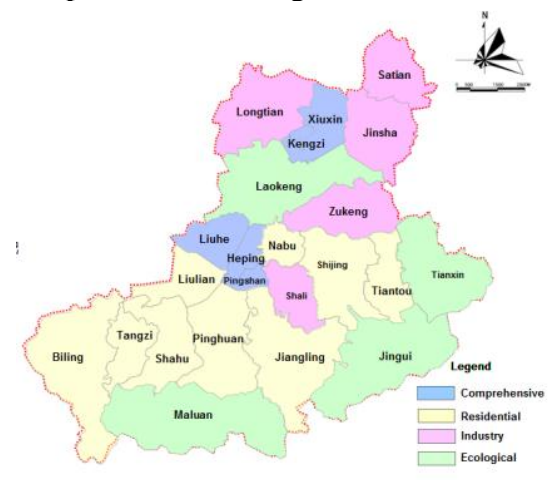

Figure 3. Pingshan community classification map

\section{B. Urban Public Service Facilities Allocation Project Type Adjustment}

The community public facilities projects must be based on the basic needs of community residents, the residents travel demand as the guide. In this paper, according to the different age structure of Pingshan New District for urban services and facilities characteristics and the present government of urban public facilities construction idea, for resident's daily use of public facilities for space allocation, in order to supplement and perfection of the Shenzhen standard.

\section{Differentiated Value Adjustment of Urban Public Facilities Indicators}

There are two methods to determine the size of the community public facilities, one is the national standard "Thousands of indicators", according to the different community population scale conversion the facilities with the construction scale; the other is the fixed interval value, corresponding in certain population size range of community, specify a value or value range. If each community facilities size is different, it is bound to increase the difficulty of construction management, it should be considered as far as possible to achieve the standardization of each type of community". 
The study that the scale of public facilities should be taken into account, and according to the location of the community, according to the allocation of indicators to complement and improve the facilities. To develop with the construction of indicators, draw lessons from other specifications and related research results to determine the size of the facilities and services, to national norms, other cities specification (corresponding to the size of the population index) as a reference, Shenzhen City standards taken as the main factor because it fit Pingshan factors, he number and size of corresponding facilities configuration is determined according to the different community population and facilities service radius.

\section{Urban Public Facilities Site Selection}

This study suggests that should according to the different types of communities in the city group characteristics and service requirements, combined with the living layout, according to the existing living center configuration of public service facilities, the use of idle residents to allocate public service facilities And the use of idle land to the public service facilities configuration, the configuration of a variety of layout of public service facilities using existing plant or temporary buildings.

\section{URBAN COMMUNITY PUBliC SERVICE FACILITIES DIFFERENTIATION CONFIGURATION}

\section{A. Comprehensive Community}

- Comprehensive community with a high level of facilities, resource sharing, improve utilization, saving land. Comprehensive community population intensive, the current situation of land tension, can be considered with the surrounding community construction. Comprehensive community with a higher proportion of men, the community sports facilities demand greatly with open space of the park plaza to complete sports and cultural recreational facilities. The comprehensive community population structure is young, appropriate set library information exchange platform and other modern cultural facilities.

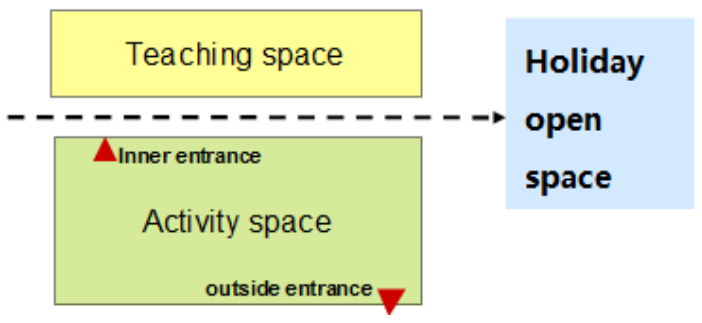

Figure 4. Pingshan school activity space pattern

- Comprehensive community population is numerous, big proportion of the floating population, police office takes standard limit. Big proportion of teenagers in the population structure, suggest community kindergarten take upper limit; Elderly population is less, the community elderly care centre take standard lower limit or nearby neighboring community combination construct.

- The comprehensive community can use the high grade facilities to share, or the comprehensive utilization of the park facilities; around the existing service center rent or built new facilities, easy to form the Recreation and sports service center. The idle rooms in the community scope, if conditions permit, can be fully utilized to transform into a supporting facilities.

\section{B. Living Community}

- Living community land is relatively concentrated, within a community can form more than one group, consider the group layout depended on facilities configuration, for the public space put the residents' committees on the center. Urban village has lots of indigenous people, it is suggested that adding the elderly care center.

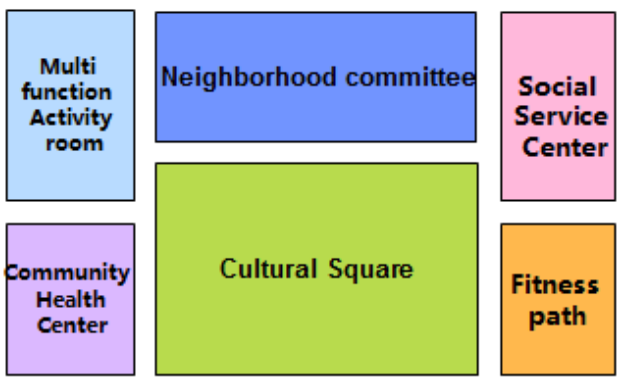

Figure 5. Layout of neighborhood committee space in Pingshan

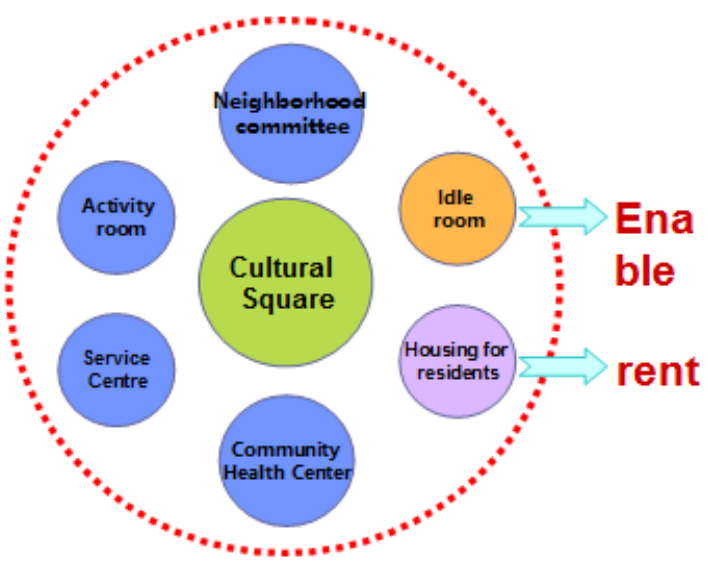

Figure 6. Public service and activity center layout

- Living community register population proportion is smaller than the flowing population, Suggestions meet the residents' normal life service facilities construction standards are limit.

- Living community facilities can be constructed around the existing community culture square or Recreation and sports facilities, if there are new Idle 
land, build new facilities room on it, if not choose spare room or renting residential facilities.

\section{Industrial Community}

- The residential land of industry type community is separated from industrial land use, suggested that independent arrangement of facilities; Residential land and industrial land blend mutually, it is recommended that facilities Shared use. Youth possess a large proportion of the population in industry type community, consider raising the proportion of business services and entertainment facilities, and can combine with open space such as park, square to construct.

- the proportion of floating population is bigger than the register population in Industry type community, suggest that police room take standard upper limit; in population structure Young and middle-aged and male is possess the bigger proportion, suggest the community kindergarten and recreational and Sports Facilities take standard upper limit Proportion of older people is less, proposed the community elderly care center take standard floor or with neighboring community combination construction.

- The idle factory transform for community facilities, part of the factory facilities recommend for community residents to open mode.

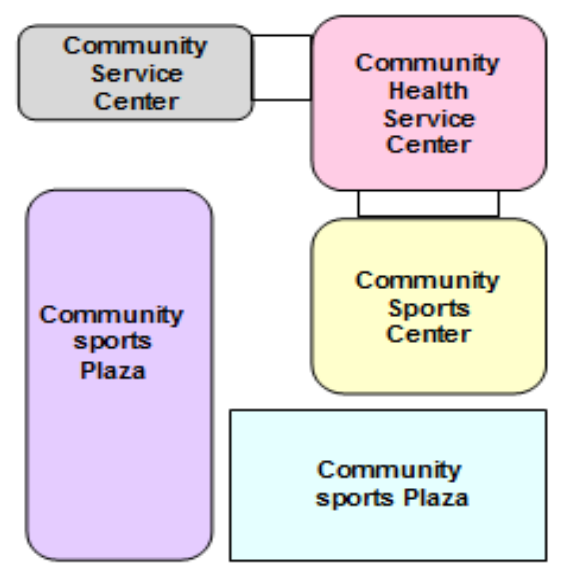

Figure 7. Sketch map of the construction of "neighborhood center"

\section{Ecological Community}

- Ecological community is located in the ecological control line, the land without new facilities recommends using the idle construction rebuilt; can combine with ecological tourism services, built temporary construction of cultural facilities; close to other communities, it is recommended sharing parts of service facilities with each other.

- Ecological community population size is small, which is far from urban community should guarantee service facilities is enough, take minimum standards.
Ecological community development of ecological tourism, police room take standard limit

- Ecological community can use the available room around building to decorate activity facilities; Considering the whole community land upgrading in the future, development of ecological tourism, part of the community can also take the construction of the temporary building model.

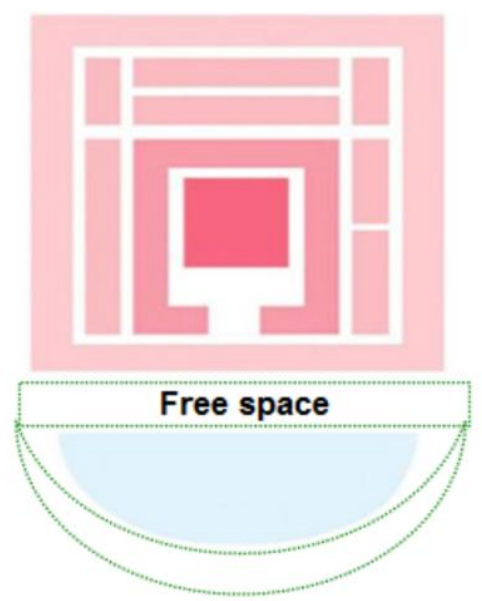

Figure 8. Layout of space around the Weiwu

\section{V.SUMMARY AND DISCUSSION}

Shenzhen Pingshan New District community construction has its own particularity, the planning of public facilities to transform the traditional way of programming and configuration to achieve the planning objectives. So we should according to the characteristics and development tendency of the urban community of different fully consider different groups of urban production and living needs, proposed facilities configuration items, the difference of index adjustment rules, and carries on the summary of the planning results of representative of the typical community, to provide a concrete implementation of the allocation of the number of table and layout method.

Shenzhen Pingshan New District as an important node in the city, under the background of urbanization development, population structure, and urban construction will continue to progress, the demand of the service facilities of the city continues to increase.

So we should put forward the sustainable public service facilities allocation system which is suitable for the overall development of the city, to solve the contradictions and problems brought by urban development and population change, enrich and perfect Pingshan community public facilities allocation system, provide the basis and guidance for our other urban public service system development. 
TABLE I. The Status Quo of Pingshan New District Facilities Configuration Features

\begin{tabular}{|l|l|}
\hline Community characteristics & Community name \\
\hline $\begin{array}{l}\text { With work, entertainment, leisure and shopping, and first-class } \\
\text { facilities in the community }\end{array}$ & $\begin{array}{l}\text { Heping community, Kengzi community, Xiuxin community, } \\
\text { Pingshan community, Liuhe community }\end{array}$ \\
\hline $\begin{array}{l}\text { To live as the main function, Community level living facilities } \\
\text { according to each group distribution, Supporting facilities } \\
\text { combined with community residents' committees centralized } \\
\text { layout. }\end{array}$ & $\begin{array}{l}\text { Tangkeng community, Shahu community, Pinghuan community, } \\
\text { Tiantou community, Liulian community }\end{array}$ \\
\hline $\begin{array}{l}\text { There are a number of industrial enterprises } \\
\text { Independent or mixed use of public facilities. }\end{array}$ & $\begin{array}{l}\text { Shatian community, Longtian community, Jinsha community, } \\
\text { Zukeng community, Shayi community }\end{array}$ \\
\hline $\begin{array}{l}\text { Community within the scope of the ecological line, } \\
\text { Far away from the center city, small population size, facilities not } \\
\text { perfect. }\end{array}$ & $\begin{array}{l}\text { Laokeng community, Jingui community, Maluanshan community, } \\
\text { Tianxin community }\end{array}$ \\
\hline
\end{tabular}

TABLE II. ANALYSIS OF THE STATUS QUO OF THE SERVICE FACILITIES

\begin{tabular}{|c|c|c|}
\hline $\begin{array}{l}\text { Facilities } \\
\text { classification } \\
\text { name }\end{array}$ & Status quo facilities content & Main Problems \\
\hline $\begin{array}{l}\text { Education } \\
\text { facilities }\end{array}$ & kindergarten, primary school & $\begin{array}{l}\text { Number of scale development imbalance } \\
\text { Private kindergarten construction is not in conformity with the specification } \\
\text { requirements } \\
\text { Floating population children education level is difficult to guarantee }\end{array}$ \\
\hline Medical facilities & $\begin{array}{l}\text { Community health service } \\
\text { center }\end{array}$ & $\begin{array}{l}\text { The construction scale is not up to standard; construction and management that } \\
\text { are not uniform; Differences between the service level; facilities not perfect, the } \\
\text { basic medical facilities is not up to standard; Medical staff liquidity is too large, } \\
\text { the professional quality is low. }\end{array}$ \\
\hline $\begin{array}{l}\text { Cultural and } \\
\text { entertainment } \\
\text { facilities }\end{array}$ & $\begin{array}{l}\text { Culture square, Cultural } \\
\text { activities, library }\end{array}$ & $\begin{array}{l}\text { Lack of sports venue area; } \\
\text { Types of sports facilities shortage; } \\
\text { Distance services; } \\
\text { Infrastructure construction standard is low; }\end{array}$ \\
\hline sports facilities & Basketball court, Sports Center & $\begin{array}{l}\text { Lack of sports venue area } \\
\text { Types of sports facilities shortage; } \\
\text { Distance services; } \\
\text { Infrastructure construction standard is low; }\end{array}$ \\
\hline $\begin{array}{l}\text { Administrative } \\
\text { facilities }\end{array}$ & $\begin{array}{l}\text { community workstation, } \\
\text { community police office, } \\
\text { community healthy service } \\
\text { center }\end{array}$ & $\begin{array}{l}\text { Community workstations without office premises } \\
\text { The community lack of the guard room } \\
\text { Lack of service personnel, Community service is different, Service center be } \\
\text { short of the prescribed area, Spatial layout is not reasonable. }\end{array}$ \\
\hline $\begin{array}{l}\text { Community } \\
\text { welfare facilities }\end{array}$ & The elderly care center & lack of the elderly community care center \\
\hline urban facilities & $\begin{array}{l}\text { Post shop, mini type transfer } \\
\text { station }\end{array}$ & poor, area do not conform to the requirements of the specification \\
\hline
\end{tabular}

\section{REFERENCES}

[1] C.Howden-Chapman P, Tobias M. Social Inequalities in Health: New Zealand [M].Wellington: Ministry of Health, 2000.

[2] J.Teitz, M.B.Toward, a Theory of Urban Public Facility Location [J]. Papers in Regional Science, 1968, 21(1):3551.
[3] C.Cox, K. R. Robert K. Location and Public Problems: A Political Geography of the Contemporary World [M]. Oxford: Blackwell, 1979.

[4] J.Lake, R.W. Rethinking NIMBY [J]. Journal of the American Planning Association, 1993(1):87-93. 